\title{
Mobilidade e Turismo: Hospitalidade no Transporte Coletivo em Caxias do Sul/RS
}

\author{
Mobility and Tourism: Hospitality in Collective Transport in Caxias do \\ Sul/RS
}

\section{Movilidad y Turismo: Hospitalidad en el Transporte Colectivo en Caxias do Sul/RS}

\author{
Simone Simon ${ }^{1}$ \\ Susana Gastal ${ }^{2}$ \\ Marcia Maria Cappellano dos Santos ${ }^{3}$
}

Resumo: Na cidade, a perspectiva aberta por uma boa rede de ligações internas confere ao morador - e, consequentemente, também ao turista/visitante que nela se encontra - independência para traçar seus caminhos para o destino a que deseja dirigir-se. Entretanto, mais do que isso, há que se considerar o transporte como um dentre os serviços que, em sua inter-relação com os processos de gestão e com os traços culturais de uma comunidade, configuram-na como um Corpo Coletivo Acolhedor (Santos e Perazzolo, 2012), no seio do qual moradores e turistas/visitantes possam sentir-se contemplados em suas necessidades e expectativas humano-sociais. Sob essa perspectiva coletiva da hospitalidade e de acordo com o Ministério das Cidades e a Secretaria Nacional de Transporte e de Mobilidade Urbana, as cidades devem oferecer os meios necessários para favorecer a locomoção de pessoas, compreendidas aquelas com necessidades especiais, implementando, dentre outras, políticas municipais específicas para o sistema de transporte. O presente artigo apresenta resultados de pesquisa qualitativa realizada no município de Caxias do Sul/RS, em 2013, com o objetivo de identificar sinalizadores de hospitalidade no transporte coletivo urbano local. A análise das condições de hospitalidade apoia-se particularmente nos conceitos de acessibilidade, legibilidade e identidade propostos por Grinover (2007). Sob esse olhar, os resultados revelam, dentre outras ações de hospitalidade nos serviços prestados pela empresa, a disponibilização de elevadores de acesso ao ônibus, interior adaptado para deficientes visuais, visibilidade de informações, transporte especial de porta a porta (PCD). Da análise decorrem algumas proposições de melhoria, ressaltando-se, no entanto, que essas ações não diminuem a importância de que haja políticas públicas que possam potencializar a qualificação permanente do transporte coletivo urbano.

1 Bacharel em Turismo pela Universidade de Caxias do Sul - Mestranda do Programa de Pós-Graduação em Turismo e Hospitalidade - Universidade de Caxias do Sul (UCS), RS, Brasil. E-mail: simone.simon1974@gmail.com

2 Doutora em Comunicação Social pela Pontifícia Universidade Católica do Rio Grande do Sul - Professora, orientadora e pesquisadora do Programa de Pós-Graduação em Turismo e Hospitalidade - Mestrado, Universidade de Caxias do Sul (UCS), RS, Brasil. E-mail: susanagastal@gmail.com

3 Doutora em Educação. Coordenadora do Mestrado em Turismo e Hospitalidade - Universidade de Caxias do Sul (UCS), RS, Brasil. Coordenadora do Núcleo de Pesquisa Turismo: Desenvolvimento Humano e social: linguagens e processos educacionais. E-mail: mcsantos@ucs.br 
Palavras-chave: Mobilidade; Hospitalidade e Turismo; Transporte Coletivo Urbano; Caxias do Sul, RS.

Abstract: In the city, the perspective opened by a good internal communication net provides inhabitantsand, consequently tourists/ visitors who are there- independence to trace their ways towards the destiny they want to reach. But, more than this, transport must be considered as one of the services which, in their inter-relation with managing processes and cultural traces of a community, set it as a Collective Welcoming Body (SANTOS and PERAZZOLO, 2012), where inhabitants and tourists/visitors can feel they are taken into account regarding their needs and social-human expectations. From this collective perspective of hospitality, and according to the Ministry of Cities and National Secretary of Transport and Urban Mobility, cities must offer the necessary means to favor people mobility, included that of handicapped ones, implementing specific municipal policies for the transport system. This article presents results of a piece of a qualitative research done in Caxias do Sul in 2013, with the aim of identifying signals of hospitality in local urban collective transport. Analysis of conditions of hospitality is particularly supported on concepts of accessibility, legibility, and identity proposed by Grinover (2007). From this view, results reveal, among other hospitality actions in services offered by the company, availability of elevators to access buses, adapted space for blind people, visibility of information, special door-to-door transport for handicapped people. From this analysis, some proposals for a better service are offered. But, it is important to highlight that these actions do not diminish the importance of existence of public policies that can strengthen permanent qualification of urban collective transport.

Key words: Mobility; Hospitality and Tourism; Urban Collective Transport; Caxias do Sul, RS.

Resumen: En la ciudad, la perspectiva abierta por una buena red de comunicaciones internas confiere al habitante $-y$, consecuentemente, también al turista/visitante que allí se encuentra - independencia para trazar sus caminos hacia el destino al que desea dirigirse. Sin embargo, más que eso, hay que considerar al transporte como uno entre los servicios, que, en su interrelación con los procesos de gestión y con los trazos culturales de una comunidad, la configuran como un Cuerpo Colectivo Acogedor (SANTOS y PERAZZOLO, 2012), en el seno del cual los habitantes y turistas/visitantes puedan sentirse contemplados en cuanto a sus necesidades y expectativas humano-sociales. Bajo esta perspectiva colectiva de la hospitalidad y de acuerdo con el Ministerio de las Ciudades y la Secretaría Nacional de Transporte y de Movilidad Urbana, las ciudades deben ofrecer los medios necesarios para favorecer la locomoción de personas, comprehendidas aquellas con necesidades especiales, implementando, entre otras, políticas municipales específicas para el sistema de transporte. Este artículo presenta resultados de una investigación cualitativa realizada en el municipio de Caxias do Sul/RS, en 2013, con el objetivo de identificar señales de hospitalidad en el transporte colectivo urbano local. El análisis de las condiciones de hospitalidad se apoya particularmente es los conceptos de accesibilidad, legibilidad e identidad propuestos por Grinover (2007). Bajo esta visión, los resultados revelan, entre otras acciones de hospitalidad en los servicios prestados por la empresa, la disponibilidad de ascensores de acceso al ómnibus, interior adaptado para deficientes visuales, visibilidad de informaciones, transporte especial de puerta a puerta para personas con deficiencia. Del análisis surgen algunas propuestas de mejoría, resaltando, sin embargo, que esas acciones no disminuyen la importancia de que existan políticas públicas que puedan potencializar la cualificación permanente del transporte colectivo urbano.

Palabras clave: Movilidad; Hospitalidad y Turismo; Transporte Colectivo Urbano; Caxias do Sul, RS.

\section{INTRODUÇÃO}

A mobilidade nas cidades médias e grandes é uma questão contemporânea, não apenas em termos de facilidade nos deslocamentos, mas, também, em termos de qualidade, nela incluída 
a hospitalidade. A realidade do crescimento urbano, portanto, demanda a busca por indicadores para avaliar a hospitalidade, que incluam a cidade como seu campo de aplicação. Presentemente, encontram-se diferentes estudos e pesquisas que, nesse âmbito, consideram a hospitalidade teoricamente e em suas práticas (Cinotti, 2009; Gérardot, 2009; Santos \& Perazzolo, 2012; Baptista, 2008; Paviani, 2014, entre outros), no entanto, o presente estudo prioriza o aporte desenvolvido por Grinover (2007), em cujos supostos teóricos apresenta como indicadores de hospitalidade, a acessibilidade, a legibilidade e a identidade. Considerando tais indicadores, a pesquisa busca avaliar que traços de hospitalidade podem ser identificados nos serviços de transporte público urbano prestados em Caxias do Sul/RS e, em decorrência, propiciar subsídios para balizar processos de gestão que possam contribuir para a qualificação crescente de relações entre mobilidade, transporte público e hospitalidade, observada a importância de atender da melhor forma possível tanto cidadãos da localidade, como turistas/visitantes a que ela acorrem. Tendo em conta a hospitalidade necessária ao trato com o usuário do transporte coletivo, indagase assim como essa se expressa na única empresa concessionária da Prefeitura Municipal, na cidade de Caxias do Sul, relativamente aos indicadores selecionados.

A cidade de Caxias do Sul possui uma única empresa detentora da concessão para a execução do transporte coletivo urbano, com contrato que se estende até 2020. Na cidade, verifica-se uma alta demanda por transporte público, atingindo uma média de 150.000 passageiros/dia.

Segunda no ranque do Estado, em população, a cidade conta com 435.564 habitantes, conforme registra o último senso do IBGE (2012).

Caxias do Sul destaca-se como polo industrial (o segundo polo metal-mecânico do país), cuja produção é reconhecida nacionalmente e no exterior. Corroboram sua força econômica, entre outros indicadores, os dados de julho 2013 constantes de documento emitido pela Câmara de Indústria, Comércio e Serviços de Caxias do Sul, referentemente aos veículos licenciados no município (2014): 185.485 automóveis; 30.496 caminhonetes; 28.991 motos; 1.738 ônibus; 1.399 microônibus.

O mesmo documento aporta outros dados relevantes com relação à mobilidade urbana: 293 mil embarques e desembarques, realizados por duas companhias aéreas, no aeroporto regional de Caxias do Sul Hugo Cantergiani, somente em 2012, números que, ao lado do transporte rodoviário, trazem sinalizadores claros de que Caxias do Sul se constitui em polo de demandas laborais, e, por conseguinte, ativando de modo significativo o desenvolvimento do denominado turismo de negócios.

Mais ainda. A cidade conta com 23 hotéis disponibilizando 3.300 leitos; 16 motéis, 407 restaurantes com diversificada gastronomia, 27 pizzarias com suas respectivas filiais e estabelecimentos delivery, 46 bares e casas noturnas e 541 outros estabelecimentos, dentre os quais, cafés, lancherias, sorveterias. Somam-se a esses elementos, segundo o Portal de Turistas de Caxias do Sul, da Secretaria Municipal de Turismo, a presença de 10 agências receptivas, 6 roteiros turísticos, 8 museus, 8 grupos/cooperativas de artesanato, 8 salas de teatro, 4 galerias de arte, 17 
salas de cinema - o que encerra o dinamismo da vida urbana e a potencialidade da cidade para crescente desenvolvimento do turismo nos mais diferentes segmentos.

É, pois, face a esse contexto, que o presente estudo volta-se para as relações de hospitalidade que se depreendem dos serviços de transporte urbano realizado pela empresa responsável. Trata-se de uma pesquisa caracterizada como exploratória, de abordagem qualitativa, com base, principalmente, em processo de observação/participação direta, acompanhada de diário de campo e de documentação por registro fotográfico realizado com uma câmera digital (112 fotos). Foram feitos embarques e desembarques em 25 das 82 linhas em funcionamento, abrangendo as zonas central, norte, sul, leste e oeste da cidade. Realizaram-se ainda entrevistas informais com a Assessoria de Qualidade, a Supervisão de Administração, a Supervisão de Recrutamento, Seleção e Capacitação, como também com a Coordenação de Transporte Urbano da empresa, objetivando obter dados afetos a esses setores, não disponibilizados na página web. Na Prefeitura Municipal, foi ouvida a Assessoria da Secretaria Municipal do Turismo, no sentido de tentar colher informações sobre projeto de uma linha de ônibus turístico, anunciada nos meios de comunicação. Complementarmente, foram visitadas: as páginas web da empresa em análise; da Prefeitura Municipal de Caxias do Sul, em especial, das Secretarias de Trânsito, Transportes e Mobilidade, de Turismo e de Obras e Serviços Públicos; e, igualmente, do Ministério das Cidades. Conforme Lourenço (2009), referindo-se à comunicação, a nova informação virtual somada e inserida ao ciberespaço propicia um passo à frente como técnica de pesquisa.

Quanto à análise dos dados, essa pautou-se, particularmente, pelas dimensões através das quais Grinover (2007) aborda a hospitalidade urbana, quais sejam: acessibilidade, legibilidade e identidade. Buscou-se ainda apoio na proposição de Corpo Coletivo Acolhedor (Santos e Perazzolo, 2012), metáfora que dá forma e identidade às comunidades, considerada a dimensão coletiva do acolhimento.

\section{TURISMO, MOBILIDADE, TRANSPORTE COLETIVO URBANO E HOSPITALIDADE}

Segundo Lickorish e Jenkins (2000, p. 138), "o transporte fornece o meio de se chegar ao destino ou, em determinadas circunstâncias, pode ser a própria experiência de turismo". No processo de globalização, aumenta a ligação de dependência entre o transporte, os empreendedores que participam desse processo e o público atendido, como bem mostraram os movimentos sociais de junho de 2013, no Brasil. O fluxo de desenvolvimento local e regional depende da rede de transporte e, cada vez mais, a qualidade de vida urbana está associada à mobilidade, inclusive nas suas ofertas de lazer e de turismo.

Um transporte público de qualidade articula territórios. Como ressalta Escriche (2010, p. 98), quando se pretende alcançar a funcionalidade turística, o ordenamento de um território exige estratégias de aproveitamento de sinergias presentes no espaço, como a inter-relação que se institui entre os três "tês": Turismo, Território e Transporte. Ainda de acordo com a autora, o 
turismo requer uma base territorial, ou "[...] um suporte físico dotado de recursos, serviços e infraestruturas que permitam criar uma oferta atrativa para a demanda" [Tradução nossa], como também transportes que facilitem o acesso aos e a circulação nos espaços turísticos.

Tem-se, pois, que a inexistência ou insuficiência de meios de transporte é fator inibidor do desenvolvimento da oferta e da demanda turísticas, o que retrai investimentos envolvendo proposições e serviços de viagens. O transporte fomenta a relação entre os destinos, a vivência de experiências por parte dos viajantes ou passageiros e a disponibilização recorrente de ligação intra e interterritórios.

$\mathrm{Na}$ cidade, a perspectiva aberta por uma boa rede de ligações internas confere ao morador - e, consequentemente, também ao turista/visitante que nela se encontra - independência para traçar seus caminhos para o destino a que deseja dirigir-se. Para os empreendedores, coloca-se como oportunidade de bons negócios. Para o poder público, significa também alavancar a qualidade de vida no local ${ }^{4}$. O transporte coletivo urbano pode igualmente dar maior visibilidade às ofertas turísticas internas e, na cotidianidade, impulsionar processos educativos formais e informais (para moradores e turistas/visitantes), assim como fomentar a valorização do arranjo produtivo do turismo.

Castaño, Moreno e Crego (2006, p. 287) realizaram estudo sobre a influência de diversos fatores psicossociais sobre a imagem que os visitantes têm de um destino. Ouvidos 1.200 turistas, concluíram que, na imagem cognitiva que esses elaboram da capital da Espanha, encontram-se os grandes museus, uma atrativa vida noturna e um transporte público cômodo que facilita os movimentos pela cidade, independentemente dos ruídos e dos problemas de tráfego com os quais possam se deparar.

Tal percepção vem reiterar que o transporte representa um importante conector do arranjo produtivo do turismo e é uma estrutura que complementa a experiência turística. $\mathrm{O}$ transporte coletivo urbano pode ser parte integrante dessa experiência, quando o turista/visitante, por exemplo, percorre uma rota e vivencia a cultura local, tomando conhecimento das diferenças que a comunidade representa em relação ao seu próprio espaço (PlanMob, 2007). O transporte coletivo urbano, portanto, desempenha papel fundamental no deslocamento de pessoas nas cidades, seja para trabalho, educação, saúde, lazer, ou mesmo, turismo. "Torna-se, pois, atribuição dos responsáveis pelas coletividades, assegurar a compatibilidade entre a "cidade que dorme", a "cidade que trabalha" e a "cidade que se diverte" (Conseil National des Transports, s.d., p. 57). [Tradução nossa]

Entretanto, mais do que isso, há que se considerar o transporte como um serviço que, em sua inter-relação com os processos de gestão e com os traços culturais de uma comunidade, configura um Corpo Coletivo Acolhedor (Santos e Perazzolo, 2012), no seio do qual moradores e

4 Considerado, na Constituição Federal, como um serviço público essencial, o transporte coletivo urbano deve ser provido diretamente pelo Estado, ou por particulares sob delegação do poder público responsável (União, Estados ou Municípios). 
turistas/visitantes possam sentir-se contemplados em suas necessidades e expectativas humanosociais. Na proposição das autoras, o espaço em que o fenômeno do acolhimento e as práticas de hospitalidade se organizam e se desenvolvem está delimitado pelo traçado da triangulação de pelo menos três vértices interligados, os quais estruturam o corpo social de um grupo ou de uma comunidade, aglutinando as dimensões fundamentais do tecido social, este concebido como sistema. São eles: a) o conjunto dos serviços disponibilizados no âmbito das relações internas/externas (abarcando a rede de segmentos de que o Corpo dispõe: transporte, alimentos, vestuário, calçados, restaurantes, hotéis, farmácias, hospitais, segurança, escolas, etc., constituindo as mãos do corpo comunitário, através das quais o microcosmo efetiva seu sistema de transações diretas, as práticas de dar e receber); b) o organismo gestor, de natureza operacional, pública e privada (que administra os recursos disponíveis e aporta os elementos básicos de infraestrutura de manutenção e de desenvolvimento do corpo social, viabilizando a organização do sistema, providenciando as condições estruturais e funcionais necessárias à consecução das demandas internas/externas); c) o capital cultural, o conhecimento gerado, compartilhado e transmitido pelo grupo/comunidade.

A hospitalidade compreendida dessa forma, em sua dimensão coletiva, vem sendo objeto de importantes contribuições teóricas no cenário científico e acadêmico, dentre as quais a de Cinotti (2009), ao propor um modelo de vetores da hospitalidade em locais de destino turístico, em que o conjunto urbano acolhedor emerge de relações entre a organização do elenco de atores envolvidos e de atributos de hospitalidade das cidades. Gérardot (2009), por sua vez, aporta a esse contexto a ideia de turismo como fator interveniente no ritmo das metrópoles, pressupondo graus de interação no "ajustamento" de ritmo da cidade em relação ao turista e deste em relação à cidade. Já Baptista (2008), acenando para a dimensão ética da cidadania urbana, cosmopolita e solidária, caracteriza a cidade como lugar de experiência de mútua autorização entre os homens, de abertura para o outro. Para Paviani (in Santos \& Baptista, 2014, pp. 84-85), “A cidade não é obviamente a sociedade, mas um modo de efetivação do conceito abstrato de sociedade e de realização da vocação social do ser humano" [...], em sendo assim, "[...] um espaço ético e educativo de experiências e ações humanas apreendidas e divididas/socializadas/partilhadas com os outros".

Nessa compreensão da hospitalidade em sua dimensão coletiva e urbana, para além da mobilidade e de seu importante papel no desenvolvimento pessoal (entendida a mobilidade como um vetor de desenvolvimento cultural, de estabelecimento de elos humano-sociais, de emancipação), a acessibilidade de todos às diferentes atividades passíveis de serem experenciadas na comunidade (formação, cultura, lazer, serviços, turismo...) torna-se "[...] um elemento de coesão social", e dessa forma, "[...] fundamenta o direito ao transporte como condição de igualdade de oportunidades para todos" [Tradução nossa] (Conseil National des Transports, s.d. p. 49), o que supõe eliminar obstáculos informacionais, tarifários, físicos referentes aos modos de deslocamento. 
Com a evolução dos ritmos urbanos, as distâncias entre as populações correm o risco de aumentar, e as desigualdades, de crescer em torno de práticas de mobilidade, tornando-se a imobilidade, a imobilidade ou a "mobilidade reduzida" um fator de exclusão crescente para diversas categorias de pessoas. Lembremonos de que em função de deficiências de nascença, de acidentes da vida, ou de efeitos de envelhecimento, perto de $30 \%$ da população já vive essa exclusão (Conseil National des Transports/Fr, s.d. p. 48). [Tradução nossa]

Esses dados referentes à França não se distinguem significativamente dos dados do Brasil, do que se depreende a importância fundamental de o sistema de transportes - no presente caso, urbano -, responder a necessidades específicas dos usuários, sejam eles moradores, turistas ou visitantes. Assim, pensar a hospitalidade urbana implica, entre outras vertentes, pensar a acessibilidade, o que pressupõe, por sua vez, uma organização e um ordenamento de lugares e atenção a normas para uso desses.

Grinover (2007, p. 82), para quem "a hospitalidade é um dom do espaço: espaço a ser lido, atravessado ou contemplado; de toda maneira, um espaço planejado", também associa a hospitalidade urbana à possibilidade de os indivíduos, os grupos sociais terem acesso, como um direito, a atividades e serviços presentes na cidade. Nesse sentido, ao referir-se à acessibilidade, evoca

[...] a disponibilidade de instalações (levando em conta os limites de capacidade dos equipamentos urbanos) ou de meios físicos, que permitem esse acesso (considerados, ao mesmo tempo, os meios de transporte e uso do solo), ou, ainda, de acessibilidade socioeconômica (levando em conta a distribuição de renda) (Grinover, 2007, p. 135).

Nas considerações do autor, evidenciam-se as dimensões tangível e intangível da acessibilidade. Entretanto, para ele, a hospitalidade de uma cidade depende também da coexistência de outras qualidades, as quais denomina "legibilidade" e "identidade".

A legibilidade diz respeito à decodificação do microcosmo urbano, ou à qualidade visual de uma cidade. Retomando o texto original de Grinover (2007, p. 144), essa qualidade está afeta à imagem mental, que, de modo especial, os habitantes e, em situações específicas, o turista/visitante fazem da cidade:

Essa imagem mental é uma referência, é uma estrutura gramatical e sintática que, por analogias e pela construção de um sistema, exprime-se pela codificação de mensagens, e, em seguida, pela decodificação dessas mesmas mensagens, cujas interpretações só poderão se dar se os códigos de emissão e de leitura forem compatíveis. Com legibilidade pretende-se indicar a facilidade com que as partes de uma cidade podem ser reconhecidas e organizadas num modelo coerente (Grinover, 2007 p. 144). 
Por outro lado, o autor (2009) também menciona o fato de a cidade constituir-se em um texto cuja leitura hoje pode ser dificultada, tal a complexidade das mensagens, a crescente polissemia das partes e os diferentes códigos dos leitores possíveis.

Quanto à identidade, esta é alcançada pela relação entre sistemas espaciais, temporais e sociais da cidade, ou ainda, por fatores culturais, tais como a organização da comunicação e o sistema de lugares.

A hospitalidade, no viés aqui proposto, ainda supõe a identidade como uma de suas marcas, entendendo-a como algo formado ao longo do tempo, mas considerando "que as velhas identidades, por muito tempo baluartes do mundo social, estão em franca dissipação, fragmentando o indivíduo moderno, até então considerado um sujeito unificado, e criando novas identidades" (Grinover, 2007, p. 148). A representação da identidade atende à compreensão das diversas formas de expressão. Termo que traduz dimensões espaciais e temporais. A identidade, para alguns, está compreendida como tradição; outros a relacionam com a história, a diferença, a representação do povo. A identidade passa ser então a cidade como ela é reconhecida. Pensandoa em relação às representações que dela faria o turista, Castrogiovanni (2002, p. 47) considera:

O lugar apresenta identidade, portanto, diferenças que constituem um único. A palavra identidade origina-se do grego idios, que significa parecido consigo mesmo. A identidade do local se caracteriza pelo conjunto de vinculações existentes em seu sistema social e natural. Ela permite a representação do lugar no todo e favorece a construção simbólica por parte do turista. O turismo nos lugares deve ter a responsabilidade em valorizar tais particularidades, (ser "parecido consigo mesmo" e não imitar os outros lugares), capitalizando-as e mostrando às comunidades que o fato do lugar ser próprio/único é o que faz existir e, portanto, ser atrativo.

Se aplicadas as teorizações, até aqui apresentadas, a empresas - subsistemas do tecido social que compõem o Corpo Coletivo que acolhe -, tem-se que, em geral, elas se empenham em aprimorar profissionais e infraestrutura para proporcionar maior qualidade ao serviço. A hospitalidade passa a constituir-se assim em um diferencial que vem sendo cada vez mais buscado para atender às exigências dos públicos interno e externo. No universo do transporte coletivo urbano, isso não pode ser diferente.

\subsection{A hospitalidade no transporte urbano de Caxias do Sul}

O trabalho realizado pela empresa de transporte público, ao longo de 28 anos, analisada pela pesquisa, tem se mostrado essencial para a mobilidade urbana em Caxias do Sul, não só pelo que o transporte público oportuniza a moradores, mas também pela sua possibilidade de levar os turistas a vivenciar a cidade plenamente, como ela realmente é. Sob esse ângulo e considerado o objetivo da pesquisa, para a análise das relações de hospitalidade associada a seus serviços aplicaram-se as dimensões propostas por Grinover (2007), já referidas: acessibilidade, legibilidade e identidade. 
Tendo por foco a acessibilidade, buscou-se pontuar a disponibilização de oportunidades de acesso aos serviços da empresa, com seus respectivos desdobramentos nos cuidados de manutenção e qualificação dos veículos e do pessoal colaborador.

Para o transporte urbano em Caxias do Sul, conta-se com uma frota de 339 ônibus ${ }^{5}$, cuja circulação compreende cerca de 5,8 mil horários/dia, em suas 82 linhas em operação, cobrindo as diferentes regiões da cidade. Os usuários dispõem ainda de veículos que fazem a ligação entre linhas.

A frota de ônibus tem em média 4,9 anos de vida, o que, além de ampliar o atendimento aos quesitos de segurança, diminui as possibilidades de panes mecânicas e consequentes ocorrências de atrasos nos horários estabelecidos de circulação. A pontualidade no acesso ao transporte corresponde a um dos valores da empresa.

Figura 1 - Frota de ônibus no transporte coletivo urbano de Caxias do Sul

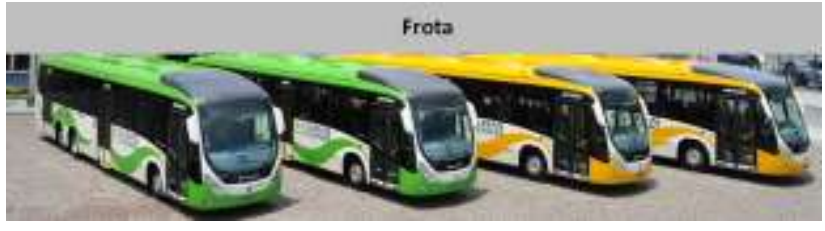

Ônibus integração interlinhas

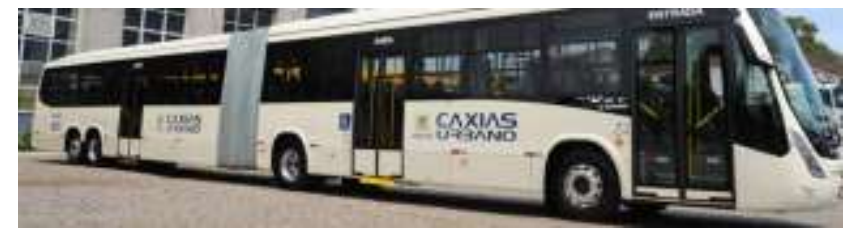

Fonte: Fotos cedidas pela empresa.

Em conformidade com o disposto na página web da empresa, com os dados obtidos nas entrevistas e com o constatado in loco durante a pesquisa, identificam-se diferentes formas de contemplar a acessibilidade aos passageiros: assentos reservados especialmente para idosos, gestantes, pessoas com deficiência e obesos, os quais possuem um braço de apoio móvel que facilita a mobilidade e melhora o conforto dos passageiros; balaústres e degraus na cor amarela para facilitar o acesso a pessoas com baixa visão, pelo contraste da cor com o fundo do ônibus; cartão passe-livre adicional para acompanhante de pessoa com deficiência, quando comprovada a necessidade de auxílio ao deficiente, no transporte; passagem especial para pessoas com dificuldade de passar a catraca, como obesos e gestantes, permitindo-Ihes descer pela porta da frente do ônibus; elevadores de embarque e espaço reservado a cadeirantes, distribuídos em 46\% da frota operacional e em todas as linhas; cartão passe-livre do idoso, que permite que usuários com 60 anos ou mais tenham acesso gratuito ao transporte coletivo urbano.

5 Dados de 2013, período de realização do estudo. 
Um diferencial que se sobressai é a linha especial de transporte porta a porta (PCD), serviço oferecido a pessoas com deficiência, mediante agendamento prévio: são disponibilizados quatro veículos com os recursos necessários para o atendimento às necessidades do deficiente.

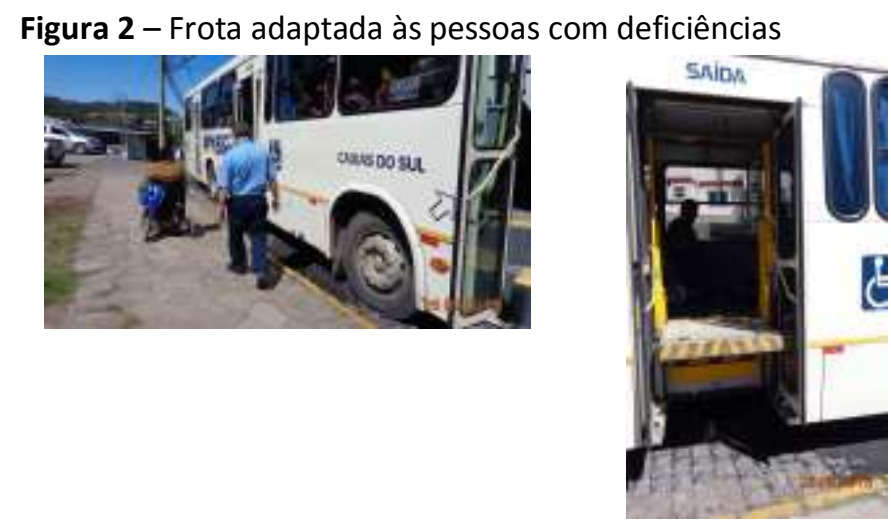

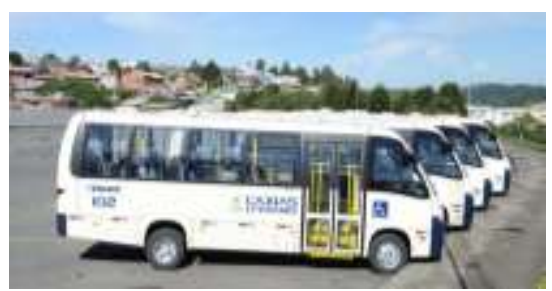

Transporte porta a porta

Fonte: Acervo pessoal das autoras.

Sob outra perspectiva, a acessibilidade, como critério de hospitalidade, reflete-se no sistema de integração tarifária, por meio da transformação do sistema radial (em que as linhas de ônibus se dirigem a um ponto único), no modelo troncalizado, em que os passageiros são coletados em estações e redistribuídos para diferentes bairros, distritos e localidades do município.

A esse conjunto de cuidados, vem juntar-se o serviço diário de manutenção de assentos e acessórios danificados.

Por outro lado, constata-se a ausência de linha de ônibus interligando o aeroporto e o centro da cidade de maneira mais efetiva e com estrutura apropriada para acomodação de bagagens, o que se configura como um elemento não condizente com o acolhimento desejável do usuário local, ou de turistas/visitantes. O mesmo se aplica ao acesso à rodoviária da cidade, atendida quase que exclusivamente por táxis: não se dispõe de um meio de transporte que comporte as bagagens, evitando-se assim a utilização de outros serviços com custo maior, ou que não sejam públicos.

Reportando ao entendimento do transporte coletivo urbano como subsistema do tecido social que compõe o Corpo Coletivo da comunidade, alguns elementos merecem ser mencionados, na medida em que apontam para descompassos nas relações sistêmicas entre os vértices desse Corpo. É de responsabilidade da administração municipal (Organismo Gestor) a qualificação permanente das paradas de ônibus e dos espaços de seu entorno. Apesar de melhorias identificadas (melhor distribuição e ampliação no número de paradas, coberturas, bancos, corredores de ônibus, etc.), verifica-se ainda, por exemplo, insuficiência de condições estruturais facilitadoras da aproximação do cadeirante aos veículos (calçadas irregulares, ausência de rampas, corrimões, entre outras). Ao olhar do usuário, no entanto, muitas vezes esses problemas passam a ser atribuídos à empresa. 
Figura 3 - Heterogeneidade de paradas de ônibus

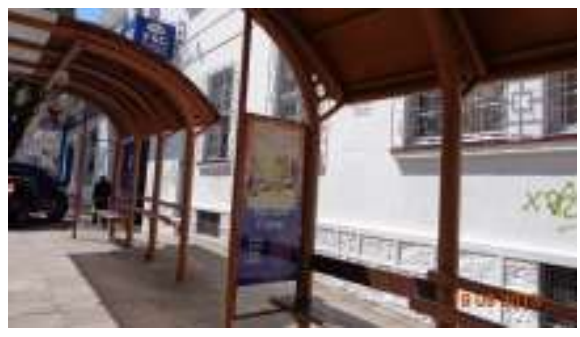

Fonte: Acervo pessoal das autoras.

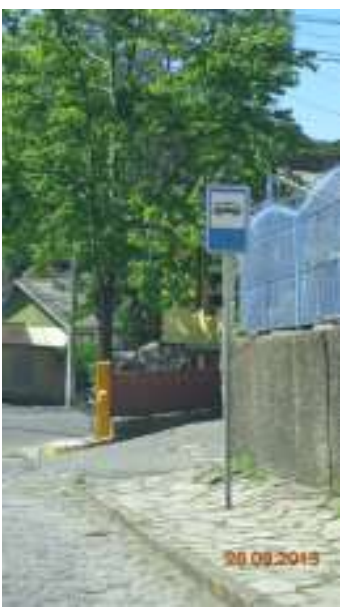

No que tange à legibilidade - indicador da qualidade visual e da comunicação de determinado local -, quando transposta ao âmbito do transporte público urbano (e, no presente caso, da empresa em análise) remete à importância de que, na execução de seus serviços, seja assegurada ao usuário a possibilidade de ir e vir de maneira adequada e fácil. Isso pode ser evidenciado, a título ilustrativo, pela disponibilização de meios legíveis de identificação de linhas, destinos e percursos. Observa-se que, em toda a frota, visores eletrônicos frontais de led, por processo de alternância contínua, permitem rápida e claramente selecionar e acessar o ônibus adequado às necessidades do passageiro.

Placas indicativas permitem também facilmente localizar as paradas de ônibus. Por outro lado, o usuário não dispõe regularmente de informações sobre as linhas a que se tem acesso na parada de ônibus. Se isso já pode acarretar dificuldades ao morador local, tanto mais acarretará ao turista/visitante. À semelhança do que é mencionado no documento Nouveaux rythmes urbains et organisation des transports, disponibilizado pelo Conseil National des Transports/Fr (s.d.) referindo-se a situações ocorrentes na França, a correspondência entre signalética e informações é frequentemente mal adaptada a deslocamentos de pessoas que não conhecem nem os códigos, nem os usos da cidade na qual estão circulando. Ressalta-se ali ser uma questão de hospitalidade urbana obrigar a que sejam cruzados os olhares do habitante, do turista, do excursionista.

Ainda com relação à legibilidade, foram identificados outros aspectos cuja melhoria pode contribuir para a hospitalidade no transporte coletivo urbano em Caxias do Sul. Observou-se falta de placas em braile nos pontos de ônibus para o acesso de passageiros com deficiência visual, insuficiente sinalização sonora na abertura de portas do coletivo e de avisos por voz, no interior do ônibus indicando as principais paradas. Não se encontram tampouco placas com orientações sobre os locais de atendimento aos clientes para esclarecimento de dúvidas e outros serviços em geral.

Com o entendimento de identidade como fator de hospitalidade, o transporte público urbano torna-se um meio de favorecimento à interação de passageiros, residentes ou 
turistas/visitantes, com aspectos histórico-sociais e culturais da localidade. O desenvolvimento do local em comparação com o global permite uma competitividade saudável em prol da participação cívica, da interação, do desenvolvimento da ação coletiva, da gestão e do modo cultural locais, fortalecendo essa identidade e permitindo experienciar como essa localidade é na realidade dos seus cotidianos. Ou seja, permite à comunidade compreender a si mesma e desenvolver um aprofundamento de suas raízes e cultura, para poder compreender-se e ser compreendida por turistas ou visitantes. Um serviço de transporte público capacitado permite que o local se torne interessante e dinâmico ao olhar de moradores e visitantes, em especial em uma cidade com alto nível econômico e potencial turístico.

A empresa analisada incentiva a participação e fomenta a cultura regional e local, contribuindo, por exemplo, com a divulgação e a promoção de eventos em Caxias do Sul, como a Festa da Uva e a Semana Farroupilha, conforme se pode observar nas Figuras 4 e 5 . No interior dos ônibus, constata-se a existência de espaços específicos para a divulgação de festas e assuntos ligados à comunidade como um todo. Por outro lado, quase a totalidade da estrutura disponível ao longo das paradas de ônibus não é utilizada para a divulgação de eventos, da história da cidade ou da própria empresa. Isso se dá em apenas algumas paradas e não de modo regular.

Figura 4 - Indicativo da dimensão "identidade": empresa divulga festa do município

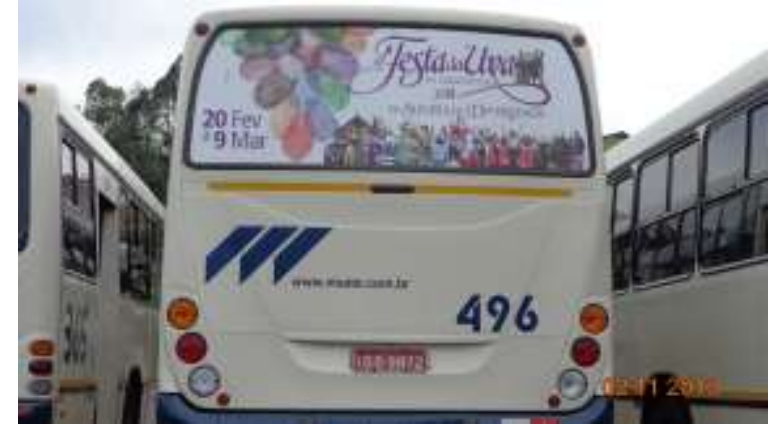

Fonte: Acervo pessoal das autoras.

Figura 5 - Indicativo da dimensão "identidade": colaborador em traje típico gaúcho durante as comemorações dos Festejos Farroupilha

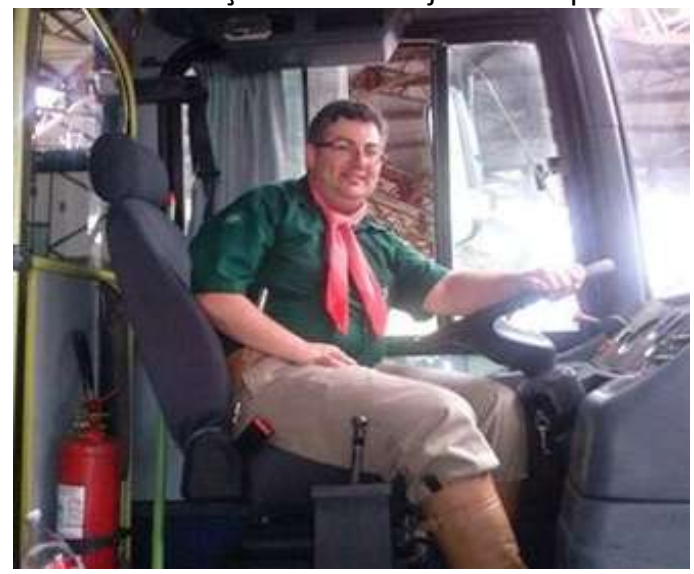

Fonte: Foto cedida pelo colaborador da empresa (publicação com autorização da pessoa fotografada) 
De outra parte, dessa ligação próxima da empresa com a cultura local associada a ações que empreende indicativas de sua preocupação com a acessibilidade e a legibilidade - tal como se aludiu anteriormente - permite depreender uma cultura organizacional que lhe é própria, ou, em outras palavras, uma organização em cuja identidade se veem impressas marcas de hospitalidade condizentes com valores e princípios que anuncia como balizadores de suas decisões e ações, dentre os quais, ética, integridade, respeito à pessoa, satisfação do cliente.

As reflexões até aqui realizadas já permitem elaborar uma síntese das relações de hospitalidade identificadas no transporte coletivo urbano de Caxias do Sul, conforme apresenta o quadro a seguir, pondo em relevo aspectos avaliados como positivos ou a melhorar, ao mesmo tempo em que são feitas sugestões para qualificação dos serviços prestados no que diz respeito aos critérios "acessibilidade", "legibilidade" e "identidade".

Figura 6 - Síntese avaliativa de relações de hospitalidade identificadas no transporte coletivo urbano de Caxias do Sul, afetas à empresa responsável (Continua)

\begin{tabular}{|c|c|c|c|}
\hline Indicador/critério & Pontos Fortes & Pontos fracos & Sugestões de melhorias \\
\hline Acessibilidade & $\begin{array}{l}\text { Dimensão e idade } \\
\text { média da frota; } \\
\text { - } \quad \text { número de } \\
\text { horários/dia; } \\
\text { - } \quad \text { úmero de linhas em } \\
\text { operação; } \\
\text { - } \text { Adequações no } \\
\text { interior dos ônibus } \\
\text { para conforto, } \\
\text { acomodação e } \\
\text { facilidade de } \\
\text { circulação de idosos, } \\
\text { obesos, gestantes, } \\
\text { deficientes físicos; } \\
\text { elevadores para } \\
\text { embarques de } \\
\text { cadeirantes; } \\
\text { - Serviço de } \\
\text { atendimento porta a } \\
\text { porta para pessoas } \\
\text { com deficiências; } \\
\text { Integração tarifária; } \\
\text { Manutenção diária de } \\
\text { assentos e acessórios. }\end{array}$ & 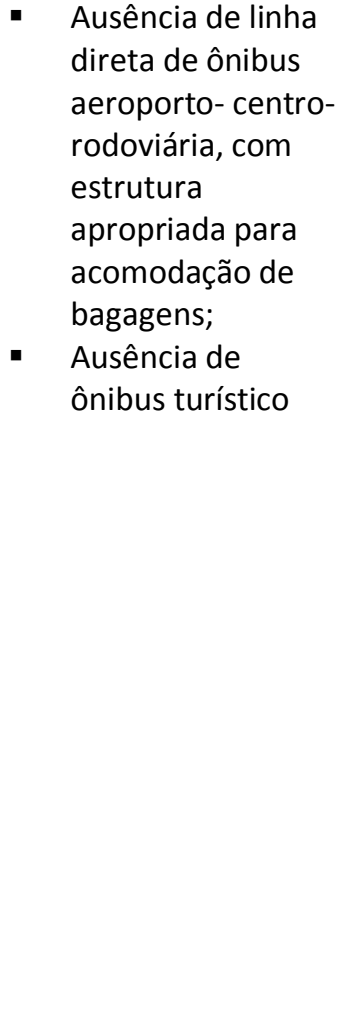 & $\begin{array}{l}\text { - Implementação das } \\
\text { linhas; } \\
\text { Disponibilização de } \\
\text { ônibus turístico; } \\
\text { Cartão para o turista } \\
\text { com código QR } \\
\text { (Código QR: código } \\
\text { de barras } \\
\text { bidimensional que } \\
\text { pode ser facilmente } \\
\text { interpretado por } \\
\text { telefones celulares } \\
\text { equipados com } \\
\text { câmeras e convertido } \\
\text { em textos interativos, } \\
\text { links ou outros - } \\
\text { cartão funcione como } \\
\text { souvenir da cidade } \\
\text { após sua utilização). }\end{array}$ \\
\hline
\end{tabular}


Figura 6 - Síntese avaliativa de relações de hospitalidade identificadas no transporte coletivo urbano de Caxias do Sul, afetas à empresa responsável

\begin{tabular}{|c|c|c|c|}
\hline Legibilidade & $\begin{array}{l}\text { - } \quad \text { Visores eletrônicos } \\
\text { frontais de led; } \\
\text { - } \quad \text { Placas indicativas das } \\
\text { paradas de ônibus. }\end{array}$ & 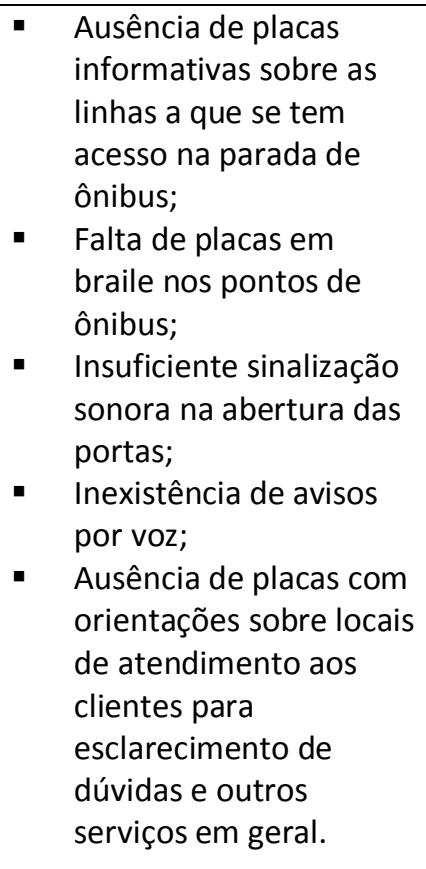 & $\begin{array}{l}\text { - Colocação de placas } \\
\text { - } \quad \text { Amara cegos; } \\
\text { de sinalizção da instalação sonora; } \\
\text { - } \quad \text { Aviso por voz no interior } \\
\text { do ônibus; } \\
\text { - Instalação de placas } \\
\text { indicando locais de } \\
\text { atendimento. } \\
\text { Criação de uma página } \\
\text { on line específica para } \\
\text { turistas/visitantes; } \\
\text { Divulgação on line de } \\
\text { linhas, locais de saída e } \\
\text { chegada e horários do } \\
\text { ônibus turístico. }\end{array}$ \\
\hline Identidade & $\begin{array}{l}\text { Divulgação de eventos da } \\
\text { cidade; } \\
\text { - } \quad \text { Integração à } \\
\text { comemoração de datas } \\
\text { comemorativas da cidade } \\
\text { e do estado. }\end{array}$ & $\begin{array}{l}\text { - Aproveitamento } \\
\text { insuficiente da } \\
\text { estrutura das paradas } \\
\text { de ônibus para } \\
\text { divulgação de eventos } \\
\text { da cidade. }\end{array}$ & $\begin{array}{l}\text { - Serviço de atualização } \\
\text { de informações sobre } \\
\text { eventos disponibilizadas } \\
\text { em placas existentes nas } \\
\text { paradas. }\end{array}$ \\
\hline
\end{tabular}

Fonte: Dados de pesquisa.

\section{NA DIREÇÃO DE CONSIDERAÇÕES FINAIS}

A concessionária para a execução do transporte coletivo urbano de Caxias do Sul mostrouse uma empresa preocupada com o bem-estar de seus passageiros, sejam eles moradores locais ou turistas/visitantes. Tal preocupação foi evidenciada em diversas passagens da pesquisa. Exemplo singular disso é o serviço que implementou o transporte porta a porta para pessoas com deficiência. Independentemente do que há a ser melhorado, cabe ressaltar a permanente atenção à capacitação de seus funcionários, no que tange aos aspectos técnicos e às relações interpessoais - conforme acentuado nas entrevistas -, como também à aquisição de produtos para que a infraestrutura física atenda à comunidade e aos usuários em geral da melhor forma.

Constantemente, tem-se presenciado nas redes de comunicação a difícil realidade enfrentada por usuários do transporte coletivo urbano no Brasil. Ao trazer à reflexão a hospitalidade na realização deste trabalho, pôde-se observar a importância do comprometimento das empresas que possuem concessões públicas, não só na qualidade dos serviços prestados, como na própria consolidação da cidade, como espaço de qualidade de vida, espaço de 
acolhimento. Nisso estão latentes interações sistêmicas entre os vértices do Corpo Coletivo Acolhedor que dá forma e identidade às comunidades, e entre esses e os subsistemas que o constituem -, no presente caso, focalizados no serviço de transporte urbano do município, abarcando elementos tangíveis e intangíveis do tecido social.

Talvez aqui, para além da especificidade do objeto da pesquisa, se possa entrever aproximações com a unitas multiplex a que se refere Morin (2005). Ao mesmo tempo em que o todo é entendido como uma macrounidade sistêmica, sem que as partes nele se fundam ou sejam com ele confundidas, essas se caracterizam por uma dupla identidade: a que lhes é própria e a que Ihes é comum, a da "cidadania sistêmica". Poder-se-ia assim supor que as imagens mentais que moradores locais, turistas/visitantes venham a construir sobre a hospitalidade no transporte urbano de Caxias do Sul - pelas características particulares dos serviços prestados pela empresa responsável -, possam ter reflexos sobre e, simultaneamente, ter refletida a imagem de hospitalidade que constroem e que vem sendo construída sobre a cidade.

\section{REFERÊNCIAS}

Baptista, I. (2008). Pedagogia Social, sustentabilidade e desenvolvimento humano. Grupo Interdisciplinar de Ética, UCP, Porto.

Brasil Acessível. Programa Brasileiro de Acessibilidade Urbana. Recuperado em 22 outubro, 2013, de http://www.cidades.gov.br/images/stories/ArquivosSEMOB/Biblioteca/BrasilAcessivelCaderno01.pdf

Câmara de Indústria, Comércio e Serviços de Caxias do Sul. Perfil de Caxias do Sul (2014). Recuperado em 15 junho, 2014, de http://www.bmaiscompet.com.br/download arquivos.asp?id arquivo=9CBA13049CAC-4B79-9BEA-79852BEF1003.

Castaño, J. M., Moreno, A., \& Crego, A. (2006). Fatores psicosociales y formación de imagenes en el turismo: un estudo de caso sobre Madrid. In: Pasos. Revista de Turismo y Patrimonio Cultural, v. 4, n.3, pp. 287-299.

Cinotti, Y. (2009). L'hospitalité touristique au service des destinations. In: Lemasson, J. P.; Violier, P. (Org). Destinations et territoires: coprésence à l'oeuvre. Québec: Edition Téoros.

Conseil National des Transports: nouveaux rythmes urbains et organisation des transports. s.d..

Distânciacidades.Com. Recuperado em 27 outubro, 2013, de http://br.distanciacidades.com/distancia-deporto-alegre-a-caxias-do-sul

Escriche, M. M., (2010). Planificación: transporte, turismo y territorio. Gran Tour: Revista de Investigaciones Turísticas. n.1, pp. 97-119.

Gastal, S. A., \& Castrogiovanni, A. C. (2002). Turismo na pós-modernidade: (des)inquietações. São Paulo: EDIPUCRS.

Gérardot, M. (2009). Comprendre la touristisation métropolitaine. In: Lemasson, J. P.; Violier, P. (org). Destinations et territoires: coprésence à l'oeuvre. Québec: Edition Téoros. 
Grinover, L. (2007). A hospitalidade, a cidade e o turismo. São Paulo: Aleph.

Grinover, L. (2009). A hospitalidade na perspectiva do espaço urbano. Revista Hospitalidade. 6(1) pp. 4-16, jun.

Instituto Brasileiro de Geografia E Estatística. Recuperado em 27 outubro, 2013, de http://cidades.ibge.gov.br/painel/painel.php?lang=\&codmun=430510\&search=rio-grande-do-sul |caxiasdo-sul linfograficos:-dados-gerais-do-municipio

Lickorish. L. J., \& Jenkins, C. L. (2000). Introdução ao turismo. Rio de Janeiro: Campus.

Lourenço, G. F. T. (2009). Hospitalidade Virtual no Turismo: do Informacional ao Comunicacional. Artigo (Mestrando em Comunicação e Sociedade) - Universidade Federal de Juiz de Fora. Recuperado em 8 outubro, 2013 de http://www.intercom.org.br/papers/nacionais/2009/resumos/R4-0717-1.pdf

Morin, E. (2005). A organização (do objeto ao sistema). In: . O método 1: a natureza da natureza. 2. ed. Porto Alegre: Sulina, p. 122-34.

Paviani, J. (2014). A função ética e educativa da cidade. In: Santos, M. M. C. \& Batista, I, (2014). Laços sociais: por uma epistemologia da hospitalidade. Caxias do Sul/RS, Educs, p.83-98.

PlanMob - PLANO DE MOBILIDADE URBANA. Recuperado em 22 outubro, 2013, de http://www.mobilize.org.br/midias/pesquisas/planmob---construindo-a-cidade-sustentavel.pdf

Prefeitura de Caxias Do Sul. Recuperado em 10 outubro, 2013 de http://www.caxias.rs.gov.br/

Perazzolo, O.A., \& Santos, M.M.C. (2012). Hospitalidade numa perspectiva coletiva:

o corpo coletivo acolhedor. Revista Brasileira de Pesquisa Em Turismo, São Paulo, v. 6, n. 1, jan./abr., pp. 3-15. Recuperado em 15 outubro, 2014 de http://www.rbtur.org.br/ojs/index.php/rbtur/article/view/484/503

Serragaúcha.Com. Recuperado em 10, outubro, 2013 http://www.serragaucha.com/pt/paginas/caxias-dosul/

Visate. Recuperado em 20 agosto, 2013 de http://www.visate.com.br/2012/index.php\#

Artigo recebido em: 02/06/2014. Artigo aprovado em: 02/12/2014 